\section{Massive Rectal Bleeding from a Dieulafoy Lesion in the Rectum: Successful Endoscopic Clipping}

The classic Dieulafoy lesion is a minute gastric mucosal defect which bleeds massively from an exposed artery. Although, only five cases of rectal Dieulafoy lesions have been reported, the methods of controlling the bleeding have differed from case to case [1-5]. We report a case of rectal Dieulafoy lesion in which the bleeding was controlled by endoscopic clipping.

An 82-year-old man underwent operation for an internal hemorrhoid using the Milligan-Morgan method. On POD 18, there was a sudden incidence of hematochezia with bright red blood. The bleeding was not from the surgical wound. The patient's blood pressure fell from 130/ $70 \mathrm{mmHg}$ to $70 / 50 \mathrm{mmHg}$, and the hemoglobin level dropped from $13.1 \mathrm{mg} / \mathrm{dl}$ to $8.6 \mathrm{mg} / \mathrm{dl}$. Urgent colonoscopy was performed. Washing the clot revealed a small mucosal punched-out lesion in the rectum, $7 \mathrm{~cm}$ proximal to the anal verge, containing an exposed vessel oozing blood (Figure 1a). There were no ulcers or erosions around the lesion. The lesion was closed with two endoscopic clips (Figure 1b). There was no further bleeding and follow-up colonoscopy 4 days later showed that the lesion had healed well.

An endoscopic diagnosis of rectal Dieulafoy lesions is not always easy, because the lesions are very small, and there are usually clots or stools in the rectum. It is important that endoscopists keep the diagnosis in mind and examine the rectum after washing it well.

Three of the five reported cases were treated by sclerotherapy under endoscopic guidance $[2,3,5]$. The other two cases were treated by direct oversewing $[1,4]$. In our patient, the lesion was clipped under endoscopic vision. We recommend this method of treatment even when the exposed vessel protrudes from the mucosa, because we have successfully used this procedure to treat gastric Dieulafoy lesions. We recommend this safe and useful procedure for this disease.

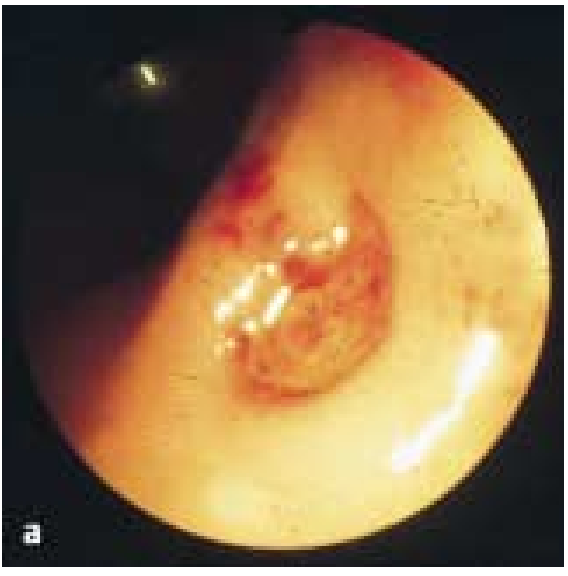

Figure 1 a A Small punchend-out lesion is seen in rectal mucosa, $7 \mathrm{~cm}$ from anal verge. A small red spot and oozing of blood are visi-

S. Nomura, M. Kawahara, K. Yamasaki, Y. Nakanishi, M. Kaminishi

Department of Gastrointestinal Surgery, University of Tokyo, Graduate School of Medicine, Tokyo, Japan

\section{References}

${ }^{1}$ Franko E, Chardavoyne R, Wise L. Massive rectal bleeding from a Dieulafoy's type ulcer of the rectum: A review of this unusual disease. Am J Gastroenterol 1991; 86: 1545 - 1547

${ }^{2}$ Abdulian JD, Santoro MJ, Chen YK et al. Dieulafoy-like lesion of the rectum presenting with exsanguinating hemorrhage: successful endoscopic sclerotherapy. Am J Gastroenterol 1993; 88: 1939- 1941

${ }^{3}$ Tooson JD, Marsano LS, Gates LK. Pediatric rectal Dieulafoy's lesion. Am J Gastroenterol 1995; 90: 2232-2233
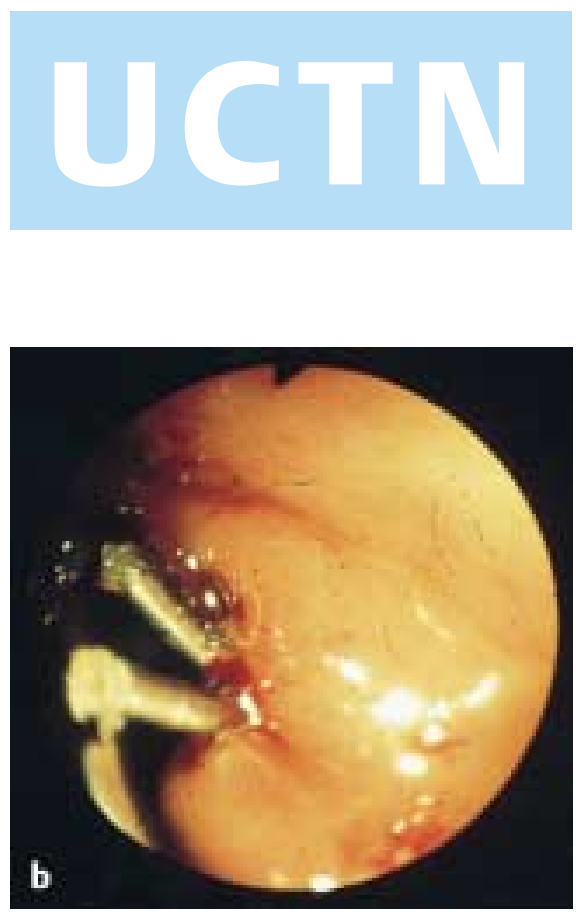

b

${ }^{4}$ Harrison JD, Calatayud A, Thava VR et al. Massive arterial bleeding from a single rectal vessel. Postgrad Med J 1997; 73: 305-316

${ }^{5}$ Yeoh KG, Kang JY. Dieulafoy's lesion in the rectum. Gastrointest Endosc 1996; 43: $614-616$

\section{Corresponding Author}

S. Nomura, M.D., Ph.D.

Department of Gastrointestinal Surgery University of Tokyo

Graduate School of Medicine

7-3-1 Hongo Bunkyo-ku

Tokyo

Japan

E-mail: e05043@h.u-tokyo.ac.jp
Fax: $\quad+81-3-39438530$ 